\title{
Editor's Note on the Text
}

With the exception of an occasional transition sentence and the concluding acknowledgement paragraph of "The Possibility of International Insurance," I have avoided any internal editing of the text. In only two instances have I broken up an original essay. First, under the chapter title "Types of Order," sections 2 and 3 of The Principles of Logic have been reprinted, while section I has been omitted. Second, only section 4, which concludes "Some Relations Between Philosophy and Science in the First Half of the Nineteenth Century in Germany," has been reprinted. I have entitled this chapter "The Methodology of Science."

Although the text of The Philosophy of Loyalty is reprinted in its entirety, I have eliminated the index, as it no longer serves its original purpose. Where possible, when citing texts from Royce's writings, I have also made reference to their location in the present edition. In my commentary, an asterisk placed after the title of a chapter or essay written by Royce signifies its inclusion in these two volumes. Royce's punctuation, spelling, and frequent use of italics has been retained throughout as have the occasional references of previous editors. The section on Bibliographic Abbreviations and the extended Bibliography will provide maximum information about the sources used throughout these two volumes. 

The Basic Writings of FOSIAH ROYCE

Volume 2 
